\title{
Bob Dylan, migraciones y globalización
}

Portelli, Alessandro

Bob Dylan, migraciones y globalización

Aletheia, vol. 10, núm. 19, 2019

Universidad Nacional de La Plata, Argentina

DOI: https://doi.org/10.24215/18521606e041

Esta obra está bajo una Licencia Creative Commons Atribución-NoComercial-Compartirlgual 4.0 Internacional. 


\title{
Bob Dylan, migraciones y globalización
}

\author{
Alessandro Portelli \\ Sapienza Universidad de Roma, Italia \\ alessandro.portelli@gmail.com
}

DOI: https://doi.org/10.24215/18521606e 041

\section{ReSUMEN:}

Alessandro Portelli tiene una larga historia de amistad con la Universidad Nacional de La Plata y con la Maestría en Historia y Memoria en particular. Ha dictado dos seminarios de posgrado en el marco de la maestría en 2013 y 2018, así como también la revista Aletheia ha publicado una traducción de un texto de su autoría (Aletheia $n^{\circ} 7$ ) y una entrevista en el marco de sus visitas al país (Aletheia $\mathrm{n}^{\circ}$ 9). En 2013 fue distinguido con el título Miembro Honorífico y en 2017 le fue otorgado el Doctorado Honoris Causa por la UNLP. Hoy volvemos a publicar un texto suyo, que transcribe la conferencia que nos ofreció en la Universidad Nacional de La Plata, el 16 y 17 de septiembre de 2019, durante una nueva visita, invitado por el Doctorado en Historia y la Maestría en Historia y Memoria de la FaHCE, para participar del Coloquio sobre Memorias Populares y realizando un encuentro con investigadores e investigadoras de nuestra casa de estudios. En la conferencia "Archivos Sonoros y cultura popular", el investigador italiano disertó sobre "Bob Dylan, migraciones y globalización" trazando un recorrido histórico y geográfico de la lírica popular de transmisión oral. En este viaje se registran las mutaciones de la canción y las transformaciones de los sujetos que la entonan a través del espacio y el tiempo, mientras permanecen las opresiones que dan lugar al canto. En la canción de Bob Dylan se concentran las versiones de sus precursores: desde el teatro del renacimiento italiano hasta el cercamiento de los campos en Escocia, desde el romanticismo europeo al folclore del Sur de Estados Unidos. Las postales musicales que reúne Portelli nos hablan también de una canción sin tiempo, una canción que se actualiza en el presente, en un mundo global que re-traza las fronteras y dictamina nuevas-viejas restricciones a la circulación de personas entre el Norte y el Sur. El canto popular del presente es entonces el de los migrantes, de las diásporas que dispersan familias y sociedades, y las "sísporas" que reúnen diferentes generaciones y culturas tan diversas en un mismo punto de llegada. En esa conjunción de lo universal y lo particular, el folklore nos trae una y mil veces los grandes temas de la humanidad: la pérdida de la inocencia, el temor de lo nuevo, la tragedia humana de la injusticia y la desigualdad. Si allá por los años ‘60 la canción de Bob Dylan nos alertaba sobre el peligro inminente de la modernidad, hoy el sentido premonitorio de esas imágenes futuristas se revierte. El paisaje sonoro que nos muestra Portelli trae la canción de los migrantes eritreos, libios, somalíes, nigerianos y senegaleses que trabajan como braseros en Italia, trae el grito de los refugiados en Veintimiglia que desafían el futuro proclamando "We're not going back". Como explica Portelli, la música es inmaterial, tiene pies, y viaja. La música no conoce fronteras, por eso la canción de los migrantes del Sur global sigue escribiendo la historia de las resistencias y resiliencias, la historia de las luchas de los pueblos por conquistar nuevas libertades.

Palabras ClaVe: Bob Dylan, Migración, Globalización, Música popular.

Buenos días a todos y a todas. Recuerdo que la segunda vez que estuve en La Plata tuve el honor y la emoción de dictar un seminario en la Comisión Provincial por la Memoria y fue muy emocionante estar en ese lugar donde se encontraba una parte importante de la memoria de la violencia del Estado y una gran cantidad de documentos realizados por los represores. Durante aquellos años, se estaba empezando a trabajar sobre una memoria alternativa, sobre una memoria democrática y popular. Se los agradezco de todo corazón. Hoy quisiera exponer ante ustedes lo que considero es la conexión entre dos proyectos en los que trabajé, pensando que eran muy distintos, pero han vuelto a encontrarse.

En 1994, un compañero que tenía un programa de radio me ofreció transmitir una canción de música popular norteamericana durante cada semana del año. Y la primera que puse, fue también la primera vez que se oyó la voz de Bob Dylan en la radio. Era esta:

A Hard Rain's A-Gonna Fall (The Freewheelin' Bob Dylan, 1963)

$$
\text { Oh, where have you been, my blue-eyed son? }
$$


And where have you been, my darling young one?

I've stumbled on the side of twelve misty mountains

I've walked and I've crawled on six crooked highways

I've been out in front of a dozen dead oceans

I've been ten thousand miles in the mouth of a graveyard

And it's a hard, and it's a hard, it's a hard, and it's a hard

And it's a hard rain's a-gonna fall

Oh, what did you see, my blue-eyed son?

And what did you see, my darling young one?

I saw a newborn baby with wild wolves all around it

I saw a highway of diamonds with nobody on it

I saw a black branch with blood that kept drippin'

I saw a room full of men with their hammers a-bleedin'

I saw a white ladder all covered with water

I saw ten thousand talkers whose tongues were all broken

I saw guns and sharp swords in the hands of young children

And it's a hard, and it's a hard, it's a hard, it's a hard

And it's a hard rain's a-gonna fall

And what did you hear, my blue-eyed son?

And what did you hear, my darling young one?

I heard the sound of a thunder, that roared out a warnin'

Heard the roar of a wave that could drown the whole world

I heard one hundred drummers whose hands were blazing

I heard ten thousand whisper and nobody listening

Heard the song of a poet who died in the gutter

Heard the sound of a clown who cried in the alley

And it's a hard, and it's a hard, it's a hard, it's a hard

And it's a hard rain's a-gonna fall

Oh, who did you meet, my blue-eyed son?

Who did you meet, my darling young one?

I met a young child beside a dead pony

I met a white man who walked a black dog

I met a young woman whose body was burning

I met a young girl, she gave me a rainbow

I met one man who was wounded in love

I met another man who was wounded with hatred

And it's a hard, it's a hard, it's a hard, it's a hard

It's a hard rain's a-gonna fall

Oh, what'll you do now, my blue-eyed son?

Oh, what'll you do now, my darling young one?

I'm a-goin' back out 'fore the rain starts a-fallin'

I'll walk to the depths of the deepest black forest

Where the people are many and their hands are all empty

Where the pellets of poison are flooding their waters

Where the home in the valley meets the damp dirty prison

Where the executioner's face is always well-hidden

Where hunger is ugly, where souls are forgotten

Where black is the color, where none is the number

And I'll tell it and speak it and think it and breathe it

And reflect from the mountain so all souls can see it

Then I'll stand on the ocean until I start sinkin' 


\section{But I'll know my song well before I start singin' And it's a hard, it's a hard, it's a hard, it's a hard It's a hard rain's a-gonna fall}

Debo decir que he quedado obsesionado con esta canción por más de cincuenta años. Y la razón de ello es porque ya la conocía antes de que él la escribiera. Bob Dylan compuso este clásico en 1962 y durante el tiempo de la Crisis de los misiles en Cuba, la grabó en el álbum The Freewheelin' Bob Dylan en 1963. Pero en 1958 yo había comprado un 45 giros de Harry Belafonte y había una canción allí que comenzaba precisamente de la misma manera: "Where have you been my blue-eyed son" ("dónde te has ido mi querido hijo de ojos azules, donde fuiste mi joven preferido"). Yo no lo sabía, pero esta canción tenía una historia muy larga. En 1629, en un texto del teatro del arte -el teatro popular improvisado - publicado en Verona, alguien citaba una canción con las mismas palabras: "Dove si sta' jersira...?” ("dónde fuiste ayer por la noche, mi querido hijo, dónde fuiste, fui a ver mi novia”). Y en 1859 Giovanni Bolza, un recopilador de folclore, la encontró al escuchar que la cantaban unas jóvenes de un pueblo cerca de Milán, Lombardía, y esta es la versión que se ha vuelto clásica en el renacimiento folclórico en Italia:

Sandra Mantovani - Il testamento dell' avvelenato:https://www.youtube.com/watch?v=KDSJ58DAmlA

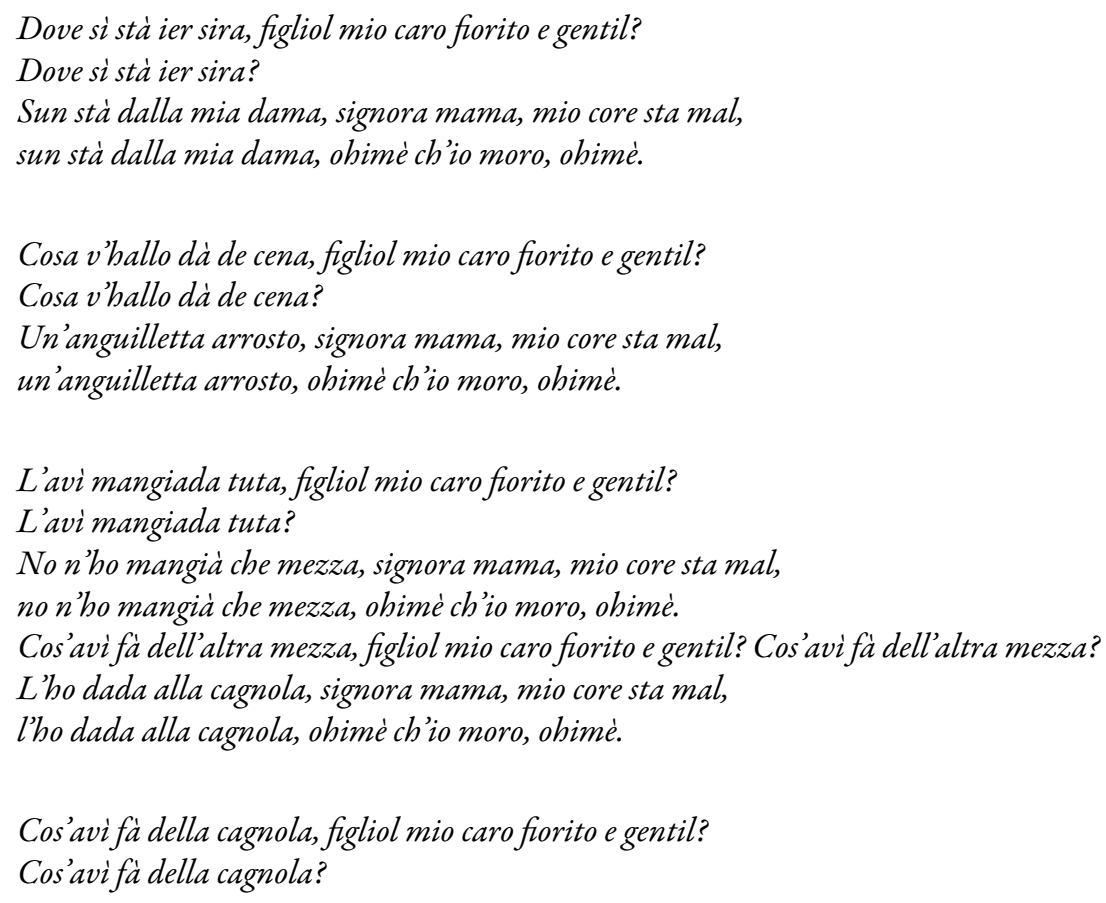

L'è morta drè la strada, signora mama, mio core sta mal, l'è morta drè la strada, obimè ch'io moro, obimè.

La v'ha giust dà el veleno, figliol mio caro fiorito e gentil La v'ha giust dà el veleno.

Mandé a ciamà el nodaro, signora mama, mio core sta mal, mandé a ciamà el nodaro, obimè ch'io moro, obimè».

Cosa lassé alla vostra mama, figliol mio caro fiorito e gentil?

Cosa lassé alla vostra mama?

Ghe lasso il mio palasso, signora mama, mio core sta mal, ghe lasso il mio palasso, obimè ch'io moro, obimè. 
Cosa lassé ai vostri fratelli, figliol mio caro fiorito e gentil?

Cosa lassé ai vostri fratelli»?

Carrozze coi cavalli, signora mama, mio core sta mal, carrozze coi cavalli, obimè ch'io moro, ohimè.

Cosa lassé ai vostri servi, figliol mio caro fiorito e gentil?

Cosa lassé ai vostri servi?

La strada da andà a messa, signora mama, mio core sta mal,

la strada da andà a messa, obimè ch'io moro, obimè.

Cosa lassé alla vostra dama, figliol mio caro fiorito e gentil?

Cosa lassé alla vostra dama?

La forca da impiccarla, signora mama, mio core sta mal,

la forca da impiccarla, obimè ch'io moro, obimè.

Como comenté, la primera vez que se tuvo noticia de los versos de esta canción fue en 1629, en el nordeste de Italia. Luego, en 1710 alguien anotaba estos versos: "Dónde has ido, hijo mío, dónde has ido mi querido hijo", en un cuadernito que llegó cien años más tarde a las manos de Francis James Child, un historiador de folclore norteamericano, que la incorporó a su recopilación de baladas narrativas del mundo anglosajón.

Esta canción de Bob Dylan tiene una poética muy modernista, el anuncio de una tragedia que va a pasar, pero que se funda sobre 400 años de historia de la cultura popular. Durante la ceremonia de entrega del Premio Nobel, en ausencia de Bob Dylan, Patti Smith eligió cantar precisamente esta canción, entre las miles de canciones que Bob Dylan ha compuesto. Por esta razón, "A Hard Rain's A-Gonna Fall” es uno de los textos más importantes en toda la poética del siglo XX en Europa y Norteamérica y que cuenta con 400 años de historia, desde aquel texto de teatro en 1629, a las folcloristas románticas a mediados del siglo XVIII y hasta el día de hoy. Yo mismo la grabé en un barrio popular de Roma, cantada por una migrante calabresa.

Esta canción, en italiano, se llama "el testamento del envenenado", en inglés se conoce como Lord Randal. Bob Dylan se inscribe en esta larga historia de cultura oral y popular y en una visión modernista catastrófica, apocalíptica de un futuro que va a caer, y que quizás ya está cayendo. Los dos textos comparten no solo el íncipit: "dónde fuiste mi querido hijo, dónde fuiste mi hijo de ojos azules", sino también el patrón de un diálogo entre una madre y un hijo, en el que la madre le pregunta "dónde fuiste", y en la canción popular el hijo responde "fui a ver a mi novia”. En la versión escocesa de MacColl, la madre habla de un hijo que se fue al bosque salvaje y, a su regreso, le pregunta "qué comiste, y qué pasó” y eso. Él responde: "hazme la cama porque estoy cansado y quiero descansar".

Esta es la versión de Ewan MacColl, un gran cantante folclórico de Escocia:

https://www.youtube.com/watch?v=0l-bCT0OedQ

O whaur hae ye been, Lord Randal, my son?

O whaur hae ye been, my bonnie young man?

I've been to the wild wood, mither, mak my bed soon,

For I'm weary wi' huntin' and I fain wad lie doon.

Where got ye your supper, Lord Randal, my son?

Where got ye your supper, my bonnie young man?

I dined wi' my true love, mither, mak my bed soon,

For I'm weary wi' huntin' and I fain wad lie doon.

What got ye for your supper, Lord Randal, my son? 
What got ye for your supper, my bonnie young man? I got eels boiled in brose, mither, mak my bed soon, For I'm weary wi' huntin' and I fain wad lie doon.

I fear ye hae been poisoned, Lord Randal, my son I fear ye hae been poisoned, my bonnie young man. $O$, aye, I've been poisoned, mither, mak my bed soon, For I'm weary wi' huntin' and I fain wad lie doon.

What's happened to your bloodhounds, Lord Randal, my son? What's happened to your bloodhounds, my bonnie young man? $O$, hey swelled and the died, mither, mak my bed soon, For I'm weary wi' huntin' and I fain wad lie doon.

What will you leave your brother, Lord Randal, my son? What will you leave your brother, my bonnie young man? The horse, and the saddle, that hangs in yon stable, For I'm sick at the heart and I fain wad lie doon.

What will you leave your sister, Lord Randal, my son? What will you leave your sister, my bonnie young man? The box and the gowd rings, $O$ mak my bed soon For I'm sick at the heart and I fain wad lie doon.

What will you leave your sweetheart, Lord Randal, my son? What will you leave your sweetheart, my bonnie young man? The tow and the halter that hangs on yon tree, And there let her hang for the poisonin' of me.

Bueno, en la versión italiana dice lo mismo, es exactamente la misma. Cambia de idioma, cambia la música, cambia todo pero los detalles son los mismos. La madre pregunta: “¿qué comiste?” y tanto en Italia, como en Escocia, como en Luisiana en los Estados Unidos la respuesta es "comí peces fritos”, y está envenenado. Entonces la madre le dice bueno, te vas a morir, y qué vas a dejar a tu madre, qué vas a dejar a tu hermana, y entonces es la misma historia. En la canción tradicional es un joven que se aventura afuera en el mundo y descubre la tragedia, la muerte, el engaño, la violencia, la traición. Vuelve, lo cuenta a su madre y hace un testamento. En el caso de la canción popular, cada miembro de la familia recibe un legado específico simbólico. En el caso de Bob Dylan es una misión poética, la canción misma es el testamento.

"Dónde fuiste ayer por la noche mi querido hijo florido y gentil. Yo fui a ver a mi novia señora madre, mi corazón está mal, que me muero. ¿Qué te dio para cenar, mi hijo florido y gentil? Le pregunta la madre. Anguila frita, señora madre. Mi corazón está mal. ¿Y qué pasó con los perros? Se murieron. Entonces te ha envenenado".

Es exactamente lo mismo en todo el mundo. Mi obsesión con esta canción hizo que recopilara 200 versiones de Lord Randal y "El testamento del envenenado". En Italia, Inglaterra, Escocia, Irlanda, Estados Unidos. Y me enteré de que el tema simbólico, el patrón, la retórica, es el mismo, pero hay un detalle que existe solo en la canción de Bob Dylan. En todas las versiones populares el héroe es joven, florido, gentil, hermoso, florido, lindo, bunny, handsome, pero nunca tiene "ojos de azul". Esto solo lo pone Bob Dylan. Entonces el sentido de la operación cultural, poética y política de Bob Dylan está en ese detalle. Está en este detalle en dos niveles: uno, el simbolismo de los ojos azules. Los recién nacidos tienen ojos azules, es el símbolo de la inocencia, de la inocencia no en el sentido de no hacer el mal, sino en el sentido de ni siquiera conocer que el mal existe. Entonces el joven se aventura afuera y tiene expectativas -como en otras canciones de Bob Dylan, come “Bob Dylan's Dream”- de que vamos a viajar siempre juntos, todo recto en una ruta 
común. Y encontramos que la ruta no es recta, que no es solo una, que hay seis rutas contorsionadas, no solo geométricamente sino también moralmente. Rutas engañadoras, rutas desleales. Y encuentra la muerte, la violencia, todo eso. Y entonces el ojo azul tiene que ver con expectativas.

"Hard Rain" es una canción muy profética. Cuando dice "Pistolas y espadas en las manos de niños", yo pensaba en la guerra civil en Sierra Leona. Y en 2001, en el encuentro del grupo de los G8 en Génova, que acabó con una violencia policíaca tremenda, mataron a un chico ahí. En una entrevista que hice con una de las alumnas de mi departamento que estuvo en Génova, ella decía: "mire, yo sabía que el Estado estaba contra, pero toda mi vida me habían enseñado que la policía estaba ahí para protegerme, y estaba en la calle bailando con flores en mi cabeza -florida y gentil-y por qué me dan una paliza, por qué me golpean”. Ese momento es precisamente cuando los jóvenes, que piensan tener derechos se encuentran con la violencia que está afuera.

Y yo me enteré de la cuestión de los ojos azules porque empecé a trabajar sobre mi librito de Bob Dylan después de pasar un año trabajando para editar una colección crítica de las novelas de Toni Morrison, la gran escritora afroamericana, otro premio Nobel, y me enteré de que la primera novela de Toni Morrison se llama "The bluest eye", "El ojo más azul". Es una novela en la que una chica negra se vuelve literalmente loca porque tiene el sueño imposible de tener los ojos del color de las estrellas de cine, de los modelos, de la publicidad. Porque los afroamericanos no tienen ojos azules. De hecho, cuando el grupo Gospel The Staple Singers hace un cover de esa canción, no cantan "mi hijo de ojos azules" (my blue-eyed son), cantan "mi hijo vagabundo" (my wandering son), porque los hijos del grupo The Staple Singers no tienen ojos azules. Peter Tosh, el gran cantor reggae, él canta "mi hijo de ojos marrones". Entonces, el ojo azul es exactamente el centro de la historia que cuenta Bob Dylan. Porque no es tanto el color de la piel, como las expectativas que van, que se acompañan con este color. El héroe de Bob Dylan solo puede ser blanco y de ojos azules porque en este país son los blancos de ojos azules los que piensan que todo está bien, normal, en el mundo. Hay dos canciones de Bob Dylan y Bruce Springsteen, "Black Cowboys" y "American Skin (41 Shots)” en que aparecen diálogos entre una madre afroamericana y un hijo. Pero son diálogos antes de que el hijo salga afuera. Y la madre lo advierte: "mira, el mundo de afuera está lleno de muerte, de droga, de policías que te agarran por el color de tu piel". Entonces el tema profundo es el tema de una inocencia que se encuentra con la violencia. Es un gran tema norteamericano. Es un tema de Hemingway, de Mark Twain, la iniciación al conocimiento del mal. Los afroamericanos tienen historias distintas. En este punto me enteré de que, en otro proyecto, estaba trabajando con gente que no tenía ojos azules.

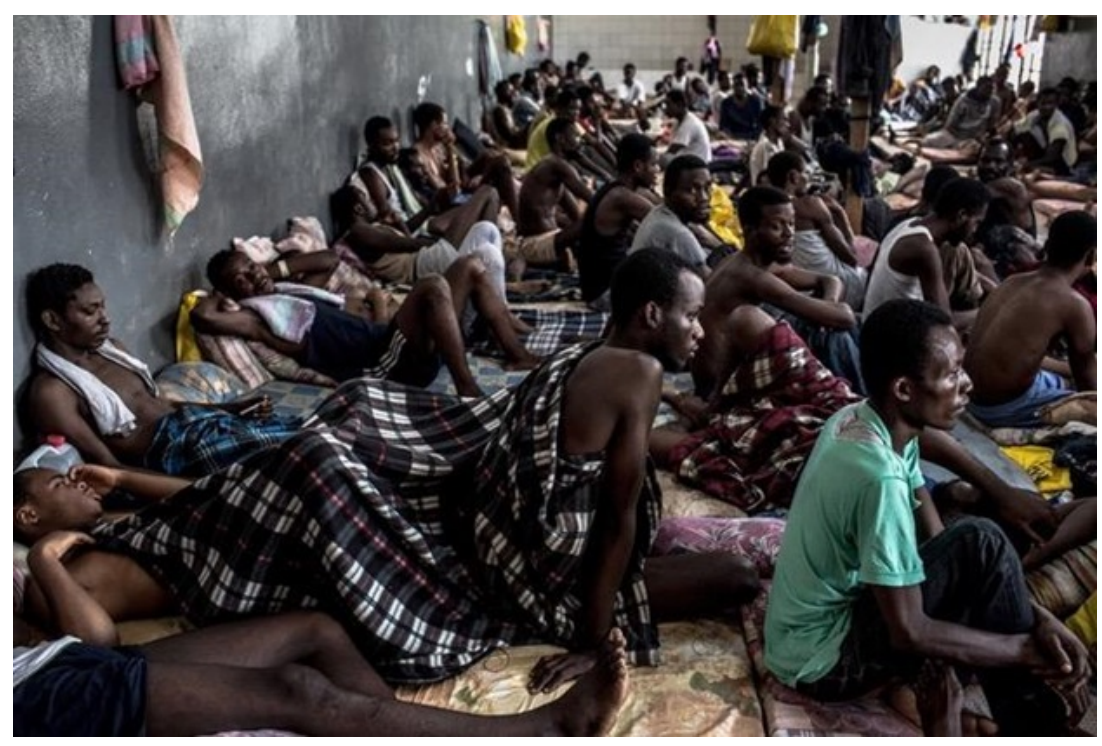

Esos son los migrantes africanos que han llegado a Libia cruzando desiertos y esperan pasar a Italia cruzando el Mediterráneo y después pasar a Francia. En Europa, hoy, teóricamente no hay fronteras. Yo puedo pasar a 
Francia, pero ellos no pueden. Han restablecido las fronteras para los que no tienen el color justo de ojos. Voy a buscar otra imagen si la encuentro. Ese es un campo de braseros en Calabria. Esos son los trabajadores que nos dan los tomates, las naranjas. Viven en estas condiciones, y se ve muy bien que tienen los ojos marrones. Y los migrantes en las rocas de Veintimiglia improvisaban "We're not going back", "No volvemos atrás".

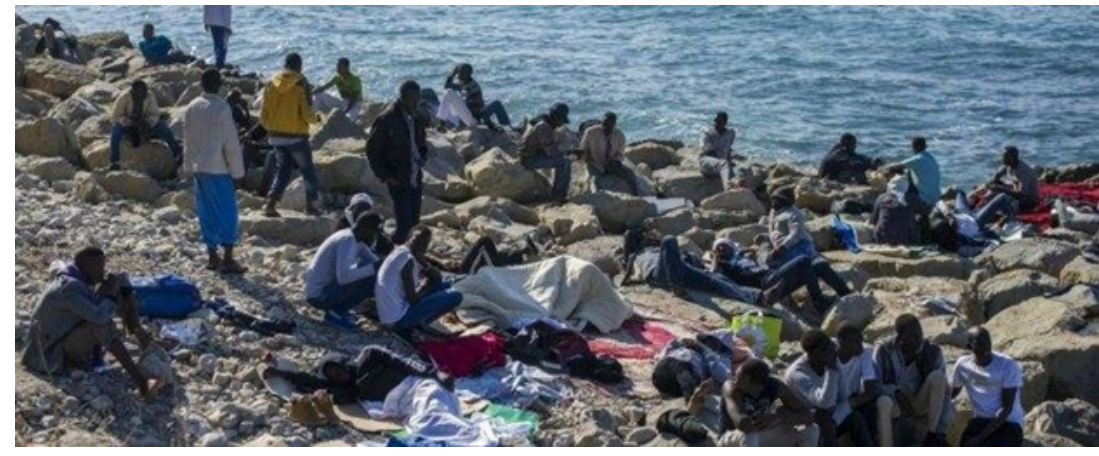

We are not going back: https://youtu.be/Hg7mx2BRxtI

Esta canción es un ejemplo perfecto de lo que pasa en la migración, porque es una forma antifónica muy africana, con las percusiones y todo. Pero el idioma es el inglés, porque es el único idioma que los eritreos, los somalíes, los nigerianos, los senegaleses, todos tuvieron la misma experiencia, el mismo viaje, y el inglés es el único idioma que comparten. Y yo no me había enterado de que "Hard rains a-gonna fall" puede ser también, precisamente, sobre ellos. Porque ellos literalmente caminaron y se arrastraron por carreteras torcidas, pisaron en medio de tristes bosques, frente a océanos rellenos de muertos, los recibieron líneas de policías con los martillos sangrando, han susurrado y hablado con la lengua rota mientras nadie escuchaba, han visto a muchas personas muriéndose de hambre y muchas personas riendo. Vinieron con expectativas, pero sin derechos; vinieron indocumentados, ilegales, pero se pararon en el océano listos para comenzar a hundirse, como casi 10.000 se hundieron en el mar Mediterráneo.

Entonces yo había trabajado desde 2009 en este proyecto sobre la música de los inmigrantes en Italia, con un marco teórico que era: si la cultura popular es la cultura de las clases no hegemónicas, de los marginalizados, ¿cuál es la clase no hegemónica, la clase marginalizada en Italia hoy? Son los migrantes, sobre todo. Entonces si la música popular de un país es la música popular de las clases trabajadoras y marginales, la música popular de Italia hoy es música filipina, kurda, senegalesa, peruana, ecuatoriana, rumana. A menudo se habla del folclore como las raíces, se les da esa entidad. Pero la música es inmaterial, y la música tiene pies, viaja. Y la música no conoce fronteras. Entonces, en ese proyecto de investigación sobre la música migrante, me encontré con este tema de expectativas, de esperanzas y lo que encuentras.

La primera grabación que hice es de un chico de Somalia. Somalia es una antigua colonia italiana, tenemos una responsabilidad muy seria con Somalia, Eritrea y Libia. Y la canción decía "soy extranjero, soy extranjero, soy hospite". "Ospite” es una palabra ambigua en italiano. Quiere decir "invitado" pero también el dueño de la casa. Entonces decir "soy invitado" en Italia, es otra cosa. "Soy africano, estoy huyendo por los animales que portan armas de la guerra civil en Somalia. Pero hoy no somos africanos, no somos europeos, entonces ¿dónde estamos todos?”. Y me explicaba, me decía “cuando llegué aquí no entendía el idioma, solo escuchaba esta palabra", que no sabe pronunciar, "straniero" (extranjero). Eso lo grabé en una escuela de italiano para migrantes, donde trabajan mi hijo y mi nuera. El niño me dijo:

me preguntaba qué significaba, debía ser un insulto, debía significar estúpido, algo así. Después de estar aquí tres meses sin llegar a la escuela entendí lo que significaba que la gente no aceptaba esos extranjeros. Que movían la cabeza tan pronto como decían la palabra, en gesto de desaprobación. En este momento entendí que era una palabra que se usaba para los refugiados, para las personas que venían de afuera, para denominar a las personas que no eran parte de este país, de este lugar. De hecho, en el primer verso también digo "hospite", y yo aprendí esta palabra cuando recibí mi permiso de residencia temporal, que permite permanecer por unos días. Los somalíes no tenemos pasaporte. Nos pidieron que pagáramos para tener un "titolo di 
viaggio", un permiso de viaje. Pero no sirve de nada. Solo puedes viajar dentro de Italia, es como un boleto de metro. Todo está aquí. "titolo di viaggio" y la palabra "straniero".

La cosa subversiva de su canción es la palabra “ospite”. Es una palabra de los medios masivos, de la retórica nacional, decimos que esperamos a esa gente y que somos muy generosos porque dejamos que vengan a nuestro país. Pero él dice "yo siempre estaré de invitado, ellos nunca permitirán que yo diga que este es mi hogar, mi país”. Entonces, en otra entrevista, en una pequeña descripción de lo que era el colonialismo, decía: "los italianos llegaron a Somalia como invitados y se volvieron buenos". El colonialismo es el cambio de significado de la palabra "hospite”. Y entonces se está preguntando “¿qué soy? ¿dónde estoy?”. Pero esta es la mayoría de las historias que encontramos.

También hay ejemplos más positivos e interesantes. En un pueblo cerca de Milán, en Lombardía, hay una liga de cultura de bases que es una liga cultural de obreros y campesinos y gente que trabaja en los establos y hay migrantes. Algunos de los migrantes que llegaron a trabajar, trabajan con vacas y ellos vienen de India, donde las vacas son sagradas y producen el parmesano. Entonces Jajit Mehta, uno de esos migrantes, se dio cuenta de que la música permite expresar algo -porque esta liga trabaja mucho con el canto popular y la canción tradicional- y empezó a escribir poemas en italiano, pero utilizando la letanía que canta su padre en el templo de Punyab. Es un sincretismo extraordinario. Y cuenta una historia distinta pero interesante.

Vengo da lontano: https://youtu.be/aq-uhp9UGnw

Vengo de muy lejos
No me voy a ir
Nací en la tierra
Donde vive mi madre
Somos ocho hermanos
Todos han salido
Uno vive en Canadá
Tres en Inglaterra
Cuatro en Italia
Todos se han ido
Vengo de lejos
No soy nostálgico
Hago un trabajo duro
Un trabajo un poco sucio
Trabajo en el establo
Vivo en la granja
Donde gritan terneros y vacas
Cantan pollos y búbos
Esta es mi casa

Entonces lo que el chico somalí está buscando es su casa, una casa. Jajit la tiene, porque logró la ciudadanía italiana, su hija se está licenciando en Medicina, tiene un trabajo. Eso le permite viajar a su casa en India, y aún invitar a sus amigos italianos, llevarlos como invitados a India. Entonces la primera cosa que a mí me llamó la atención es esta cosa de una diáspora en que una familia está en cuatro continentes: en Italia, en Inglaterra, en Canadá, en India. Y no tengo nostalgia, no estoy nostálgico, porque él sí puede volver atrás. El problema de los migrantes de Veintimiglia es que si vuelven atrás no pueden regresar otra vez.

Bueno, en Lord Randal, el héroe que se va de casa y su novia lo mata, lo envenena. Vuelve a casa y su madre le dice "haz el testamento". ¿Por qué la novia lo mata? ¿Qué novia es esta que lo mata? Y qué madre es esta que cuando el hijo se está muriendo le pregunta: “¿Qué me dejas?”. Esa sería una pregunta correcta si se tratara de una novela, de una película con personajes que tienen una psicología, tienen sus razones, todo eso. En la balada popular, se ha vuelto reducida al mínimo esencial, porque al transmitirse oralmente la memoria lo reduce a lo que es esencial, central. Después en la performance se añaden detalles y todo. Pero básicamente, 
¿por qué la novia lo mata y por qué la madre le pide que haga testamento? Bueno, con el tiempo, Lord Randal se volvió una de las canciones más importantes de todo el mundo atlántico desde Calabria a Luisiana.

Pero el siglo XVII fue el siglo en el que se pasaron las leyes de los recintos, se privatizaron las tierras comunes, se aprobaron las leyes contra los vagabundos, en el que el campesinado -más o menos pobre pero que tenía recursos para sobreevivir- se volvió un proletariado sin tierras, sin recursos, vagabundos e ilegales. Porque el tema de Lord Randal es esta oposición entre la casa y el bosque, la madre y la novia, entre lo que es seguro, conocido, familiar, y lo nuevo, el mundo de afuera. Y el mundo de afuera, la novedad del progreso para las clases que han creado y transmitido la cultura de la canción popular, no siempre es positivo. ¿Cuántas veces para esta gente la novedad, la modernidad tuvo la forma de guerras, violencias, invasiones, expropiaciones, una modernidad que privatiza los bienes comunes? Por eso, lo nuevo, es muy peligroso. Entonces la chica mata al héroe precisamente porque es la novia, la novedad, lo nuevo. En las versiones del sur de Italia, la madre pregunta: “¿Dónde te lo sirvió? En un plato nuevo. ¿Y dónde lo cocinó? En una paella nueva”. Lo nuevo es una amenaza para la supervivencia de una comunidad que está continuamente invadida. Son catástrofes naturales, son plagas, terremotos, todo eso.

Y es lo mismo en la canción de Bob Dylan. El futuro está llegando en la forma de una lluvia mortal. Hay una diferencia. En la canción de Bob Dylan, lo único que el héroe puede hacer es dejar un testimonio. Dejar su testamento en la canción. En la versión popular, el hecho de que el chico haga un testamento es un signo de que el héroe está muriendo pero su familia, su sociedad, sobreviven. Es un símbolo de la resistencia y de la resiliencia de las culturas populares. Una de las cosas que siempre me encantaron de esta balada es que es la misma en todo el mundo pero es distinta en cada pueblo. Sobre todo el testamento es una representación simbólica de los papeles sociales de los miembros de la familia. Y cambia en el tiempo y cambia en el espacio. Por ejemplo, en la versión que se recopiló en el norte en el siglo XVIII, decía: “¿Qué le dejas a tu madre? Mi palacio y mis caballos". En la versión que yo encontré que venía de la Calabria rural, de la Calabria pobre, decía: “QQué le dejas a tu madre? Ojos para que llore”. Porque ser viudas en el sur rural de Italia es llevar negro toda la vida. Cambia en Lombardía: “QQué le dejas a tu madre? Mi palacio”, es un contexto barroco. En Carolina del Norte: “¿Qué le dejas? Mi plantación”. Es un ejemplo de una resistencia, de una sobrevivencia.

¿Entonces la cultura popular es conservadora? No es así, porque hay baladas que tienen más o menos la misma historia, y la misma difusión, que dicen lo opuesto. Hay una canción, que también está en todo el mundo de idioma inglés, que se llama "The maid freed from the gallows". "La chica que la saludaron de la huerta”, que también se origina en Italia, en Sicilia del siglo XVI, que es la historia de una mujer que la raptaron los piratas sarracenos y la llevan de puerto en puerto para obtener el rescate. El padre viene y ella le dice “¿trajiste oro, trajiste plata para salvarme, cuánto tienes?”, pero el padre responde: "No, es demasiado, prefiero perderte a ti que perder el dinero". Entonces los conocidos y familiares la dejan morir, pero entonces llega el novio y él dice: "Prefiero perder todo el dinero pero salvarte a ti". Entonces en este caso es lo nuevo lo que salva.

El problema no es que la cultura popular sea conservadora, que lo nuevo sea en sí bueno o sea malo. Es una pregunta. Las culturas no son blanco y negro, las culturas son preguntas: ¿Qué vamos a hacer con la historia? ¿Qué relación tenemos con la historia? ¿La historia es una amenaza, una esperanza? Porque lo nuevo es mortal, pero no podemos renunciar al futuro. Entonces ese tema tiene que ver con la pregunta de qué relación tiene el mundo popular con la Historia. Lo mismo pasa con Bob Dylan, porque en 1962 la lluvia es mortal, "A hard rain”, es dura, las aguas son mortales, en el océano solo puedes hundirte. Un año después escribe otra canción "The times they're changing”, los tiempos están cambiando, donde las aguas crecen, y son las aguas de la liberación, son las aguas de la revuelta, y entonces Bob Dylan se pregunta: "¿qué va a pasar, el apocalipsis o la liberación?”. En el caso de Bob Dylan, según todo su trabajo más reciente, es el apocalipsis.

Hay otra relación entre la canción de Jajit y Hard rain. Porque la canción de Jajit habla de su hogar, "esta es mi casa”, pero habla también de la globalización. Todos se fueron, en Canadá, en Inglaterra, en otras partes 
de Italia. El tema de la migración y de las culturas populares, de cómo circula la cultura, también tiene que ver con la globalización. Pensé en dos historias.

La primera es la de un fotógrafo que se llama Mark Edwards, que es un fotógrafo que se ocupa del medioambiente, cuenta que se encontraba en el desierto del Sahara, se había perdido, y lo encontró un nómada Tuareg, que lo lleva a su campamento, enciende el fuego, y pone un cassette y sale la voz de Bob Dylan cantando "A hard rains a-gonna fall” en el medio del desierto del Sahara. Así Mark Edwards se enteró de que la canción tal vez en el contexto histórico es el del peligro de la energía nuclear, la bomba atómica, todo eso. Pero si la escuchas hoy habla también de la catástrofe del medio ambiente sobre los océanos muertos, las lluvias ácidas; y entonces Mark Edwards hice un libro en el que cada línea de "Hard rain" se acompaña de una imagen de la catástrofe nuclear. A mí me encanta cuando dice "A White man", un hombre blanco que llevaba un perro negro, y las imágenes de Abu Ghraib y los soldados americanos con el perro negro que muerde a los prisioneros iraquíes.

La segunda es que en 2017 visité la ciudad de Shillong, era la capital de Hassan, en el nordeste de India, un lugar trágico, de guerras. Pero Shillong, dicen también los diarios que está obsesionada con Bob Dylan. El evento más importante de la vida cultural de Shillong es el 24 de mayo, el día del cumpleaños de Bob Dylan. El lugar más importante de esta ciudad es el Bob Dylan Café, donde con las letras de las canciones de las canciones de Bob Dylan en el frigo con las Coca-Colas, y hay un músico local que las canta todas a su manera. Entonces no solo Shillong, sino el año antes fui a Calcuta, a la Universidad de Jadavpur y en la pared había un graffiti con los versos de Bob Dylan.

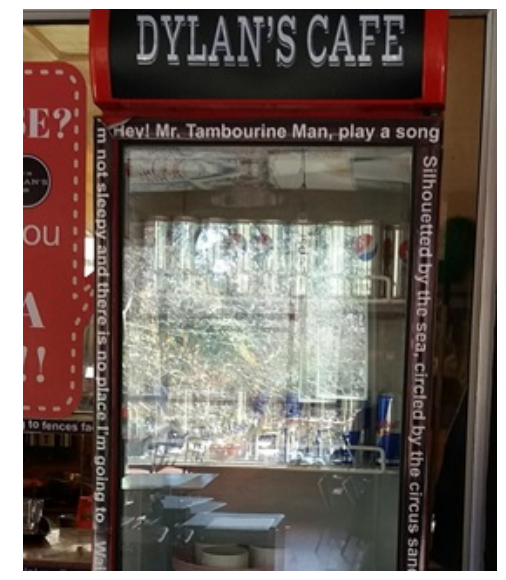

Entonces me pregunto: ¿cómo ha llegado Bob Dylan al desierto del Sahara y a partes de India a las que él nunca fue? Y lo sabemos: es el encuentro afortunado de una industria cultural -porque no todo lo que hace la industria cultural es necesariamente malo- con las pasiones de los jóvenes de todo el mundo, que hace que una canción, una música circule por todo el planeta y la compartan jóvenes de América, de India, de Argentina, de Italia. Es un tipo de globalización en que se encuentra la industria cultural y un movimiento global de revuelta juvenil, estudiantil.

Para entender cómo viajó el testamento desde Verona a Calabria, a Aberdeen, a Kentucky, tenemos que imaginar, porque no tenemos datos. Tenemos que usar la imaginación e imaginar una Europa y un Atlántico al albor de la modernidad, en que una historia y un modo de cantarla viajan, cambian, evolucionan, se adaptan, son llevadas por peregrinos, comerciantes, soldados, viajeros, artistas de calle, mendigos, misioneros, deportados, exiliados, todo tipo de personas a menudo invisibles para la Historia con H mayúscula. Pero están en la historia y la hacen. Y tenemos que imaginar un Atlántico que está cruzado por migrantes, navegantes, náufragos. Una América que se expande, que lleva esa historia a las montañas Apalaches y el Oeste. Y esta es lo que tenemos que cambiar en la manera de pensar el folclore. Porque siempre se habla de raíces. Como si la cultura tuviera que estar siempre plantada en el mismo lugar. Siempre se habla del folclore local, de las raíces, 
pero no es esto. Si tiene raíces, también tiene ramas y viaja. Y hoy, ¿qué es nativo? ¿qué es auténtico, en las culturas que están creciendo bajo nuestros ojos hoy, con los migrantes? Yo tengo un ejemplo: hay un libro de Werner Sollors, un crítico cultural alemán que enseña en Harvard tiene una esposa italiana. Él dice: mira, siempre se habla de etnicidad, como si los migrantes solo tuvieran que conservar los rasgos originales de su cultura; entonces al hablar de etnicidad se dividen. Los bolivianos tienen una etnicidad, los peruanos tienen otra. Pero lo que está pasando es que todos los migrantes, los bolivianos y los peruanos y los venezolanos, todos convergen en el mismo lugar, en Argentina o en Italia. Se hablaba de diáspora, gente que de un lugar se va a todo el mundo, pero tenemos también que hablar de lo opuesto y no tenemos una palabra para eso. Yo digo "síspora", cuando desde todo el mundo todos vienen hacia el mismo lugar. Entonces tu puedes ser de Ucrania, de Ecuador, de Senegal, de cualquier lugar, pero te encuentras con la misma policía, la misma burocracia, el mismo racismo, la misma pobreza.

Me gustaría dar un ejemplo de cómo la convergencia y la diáspora pueden alimentarse mutuamente. Hay una canción que muchos inmigrantes aprenden, y sobre todo sus hijos la aprenden en la escuela. Es la canción partisana de la Resistencia, "Bella ciao", que reelabora una antigua balada como canto de lucha contra el invasor nazi. Migrantes de todo el mundo, reunidos en Italia, cantan "Bella ciao". Al mismo tiempo, sin embargo, la canción se ha expandido desde Italia por todo el mundo: la han cantado en Cle en las manifestaciones contra la desigualdad y la marginalidad, la han cantado en la plaza de París, y se ha convertido en un himno de liberación en Kurdistán. En este video, tres músicos kurdos exiliados en Italia cantan "Bella ciao" junto a un coro multiétnico del que forman parte italianos, senegaleses, rumanos y bengalíes.

Bella ciao: https://youtu.be/Hv6Zl_LjPd0

Pero para acabar con algo menos dramático, en este proyecto de recolección de música migrante. Tuve unos encuentros en una escuela en un barrio popular de Roma, que es una escuela en la que el 35\% de los chicos son migrantes o son italianos de primera generación con padres migrantes. Y recogí las canciones de las madres de esos chicos. Y una señora china me cantó una típica canción china que se canta el último día del año para los chicos. Es una canción china tradicional, que va así:

Chen Lisao/Buon Anno Novo: https://youtu.be/X3QsnngbAfc

En una entrevista con una cantante casi profesional de Eritrea, ella cantaba la misma cosa. Cantaba una canción de bautismo que se canta en Eritrea y tenía la música de Fréres Jacques. Y hace dos semanas estaba en el tren, volvía de Milán a Roma, y veo a una señora china con sus cuatro hijos. ¡Y los chicos cantan, y cantan Fréres Jacques en chino! Bueno, el problema es que aún son invitados. La ley en Italia permite que tú tengas un pasaporte italiano si eres argentino de cinco generaciones pero tienes un tatarabuelo que venía de Italia. Pero no tienes la ciudadanía aunque hayas vivido toda tu vida en Italia y no tienes el color adecuado de ojos. Estos chicos no son ciudadanos. No pueden votar. No tienen derechos. Pero "aquí están”, y como dice Yayit, "no soy nostálgico", "aquí están” y "no vuelven atrás".

\section{BY-NC-SA}

